\title{
EVALUATION OF STATIC PRESSURE BEHAVIOR IN AN OSCILLATING WATER COLUMN WAVE ENERGY CONVERTER
}

\author{
E. A. Pinto Jra, \\ M. das N. Gomes ${ }^{b}$, \\ L. A. O. Rocha ${ }^{\mathrm{c}}$, \\ E. D. dos Santos ${ }^{a}$, \\ and L. A. Isoldi ${ }^{\text {a }}$ \\ ${ }^{\mathrm{a}}$ Universidade Federal do Rio Grande \\ Pós-Graduação em Engenharia Oceânica \\ Escola de Engenharia \\ Bairro Carreiros \\ Rio Grande, RS, 96201-900 Brasil \\ edis.antunes@hotmail.com \\ elizaldosantos@furg.br \\ liercioisoldi@furg.br \\ ${ }^{\mathrm{b}}$ Instituto Federal de Educação, Ciência e \\ Tecnologia do Paraná \\ Paranaguá, PR, 83215-750, Brasil \\ mateus.gomes@ifpr.edu.br \\ ${ }^{c}$ Universidade do Vale do Rio dos Sinos \\ Pós-Graduação em Engenharia Mecânica \\ Bairro Cristo Rei \\ São Leopoldo, RS, 93022-7500 Brasil \\ luizor@unisinos.br \\ Received: February 28, 2019 \\ Revised: March 21, 2019 \\ Accepted: April 22, 2019

\section{ABSTRACT} \\ The international scenario of non-renewable resources scarcity coupled with \\ increasing energy demand are incentives for the diversification of the \\ world's energy matrix with a focus on renewable energy sources. Among \\ these sources, energy from sea waves is especially attractive because its \\ global resource is estimated around $2 \mathrm{TW}$, comparable to the average \\ electrical power consumed worldwide each year. There are currently several \\ technologies proposed for the sea wave energy conversion into electricity. \\ Among them it stands out the Oscillating Water Column (OWC) converter, \\ which basically consists of a hydropneumatic chamber and a turbine duct \\ where a turbine is installed. Its chamber is opened below the sea water free \\ surface while the turbine duct outlet is free to atmosphere. Inside the \\ chamber the water free surface oscillating movement produced by the \\ incident waves causes the air to flow through the turbine duct and to \\ activate the turbine, so the OWC principle of operating can be approximated \\ to a cylinder-piston system. Therefore, one of the methodologies used in the \\ computational modeling to simulate the operating principle of this device is \\ the Piston Methodology, which simplifies the problem analysis considering \\ only the air flow through the OWC converter. Among the phenomena that \\ occur within the OWC device, the static pressure behavior is arguably one \\ of the most important because it is through it that it is possible to estimate \\ the hydropneumatic power and the converter efficiency. Thus, the objective \\ of this work is to evaluate the static pressure behavior within the OWC, \\ using the Piston Methodology, by imposing a monochromatic wave \\ boundary condition in an axisymmetric domain. Among the obtained results \\ it was inferred that the static pressure, in this case, depends directly on the \\ flow acceleration and it is strongly influenced by the vorticity generated in \\ domains with a change of area. \\ Keywords: oscillating water column; piston methodology; axisymmetric \\ domain; static pressure; harmonic movement \\ a flow acceleration, $\mathrm{m} / \mathrm{s}^{2}$ \\ A cross-sectional area, $\mathrm{m}^{2}$ \\ $\mathrm{A}_{1} \quad$ inlet cross-sectional area, $\mathrm{m}^{2}$ \\ $\mathrm{A}_{2} \quad$ outlet cross-sectional area, $\mathrm{m}^{2}$ \\ $\mathrm{C}_{\varepsilon 1} \quad \kappa-\varepsilon$ model dimensionless constant \\ $\mathrm{C}_{\varepsilon 2} \quad \kappa-\varepsilon$ model dimensionless constant \\ $\mathrm{C}_{\mu} \quad \kappa-\varepsilon$ model dimensionless constant \\ e wall roughness, $\mathrm{m}$ \\ $f \quad$ friction loss factor \\ $\vec{g} \quad$ gravity acceleration, $\mathrm{m} / \mathrm{s}^{2}$ \\ $\mathrm{G}_{\mathrm{K}} \quad$ turbulence kinetic energy generation, $\mathrm{kg} / \mathrm{m} \cdot \mathrm{s}^{2}$ \\ $\mathrm{H}_{\mathrm{T}} \quad$ total pressure loss, $\mathrm{N} / \mathrm{m}^{2}$ \\ $\mathrm{K}_{\mathrm{p}} \quad$ minor loss coefficient \\ L domain total length, $m$ \\ $\mathrm{L}_{1} \quad$ hydropneumatic chamber length, $\mathrm{m}$ \\ $\mathrm{L}_{2} \quad$ turbine duct length, $\mathrm{m}$ \\ $\mathrm{m}$ mass of the fluid, $\mathrm{kg}$ \\ $\mathrm{p}$ pressure, $\mathrm{N} / \mathrm{m}^{2}$ \\ $\mathrm{P}_{1}, \mathrm{P}_{2}$ static pressure, $\mathrm{N} / \mathrm{m}^{2}$ \\ $\mathrm{R}_{1} \quad$ inlet radius, $\mathrm{m}$ \\ $\mathrm{R}_{\mathrm{e}} \quad$ Reynolds number \\ $\mathrm{R}_{1} \quad$ inlet radius, $\mathrm{m}$ \\ $\mathrm{R}_{2} \quad$ outlet radius, $\mathrm{m}$ \\ $\mathrm{S}$ source term \\ $\mathrm{S}_{\mathrm{K}} \quad$ source term (mean strain rate for $\mathrm{\kappa}$ ), $\mathrm{m}^{2} / \mathrm{s}^{2}$ \\ $\mathrm{S}_{\varepsilon} \quad$ source term (mean strain rate for $\varepsilon$ ), $\mathrm{m}^{2} / \mathrm{s}^{2}$ \\ $\mathrm{t}$ time, $\mathrm{s}$ \\ $\mathrm{T}$ wave period, $\mathrm{s}$ \\ $v \quad$ velocity, $\mathrm{m} / \mathrm{s}$ \\ $v_{l}, v_{2}$ inlet and outlet velocity, $\mathrm{m} / \mathrm{s}$ \\ $\vec{v} \quad$ velocity vector, $\mathrm{m} / \mathrm{s}$
}

\section{NOMENCLATURE}

D diameter, $m$

$\mathrm{F}$ force, $\mathrm{N}$

$\mathrm{H}$ wave height, $\mathrm{m}$ 
$\mathrm{V}$ domain volume, $\mathrm{m}^{3}$

$\mathrm{Z}_{1}, \mathrm{Z}_{2}$ height, $\mathrm{m}$

\section{Greek symbols}

$\varepsilon \quad$ energy dissipation rate, $\mathrm{m}^{2} / \mathrm{s}^{3}$

$\kappa$ turbulence kinetic energy, $\mathrm{m}^{2} / \mathrm{s}^{2}$

$\rho$ density, $\mathrm{kg} / \mathrm{m}^{3}$

$\mu \quad$ dynamic viscosity, $\mathrm{kg} / \mathrm{m} . \mathrm{s}$

$\mu_{\mathrm{t}} \quad$ eddy viscosity, $\mathrm{kg} / \mathrm{m}$.s

$\rho$ density, $\mathrm{kg} / \mathrm{m}^{3}$

$\sigma_{\kappa} \quad$ Prandtl number for $\kappa, \mathrm{kg} / \mathrm{m} . \mathrm{s}^{2}$

$\sigma_{\varepsilon} \quad$ Prandtl number for $\varepsilon, \mathrm{kg} / \mathrm{m} . \mathrm{s}^{2}$

\section{INTRODUCTION}

According to Jenniches (2018), the transition from the global energy system to matrices based on renewable sources is one of the main current trends, allowing not only the diversification of energy production but also its decentralization.

For Lisboa et al. (2018), the extraction of energy from the sea waves can be an excellent alternative to the increase in the demand for renewable energy, since its global resource is approximately 2 TW per year, being equivalent to the average electrical power consumed annually in the world.

According to Falcão and Henriques (2016), among the possible technologies for the energy conversion of the sea waves the Oscillating Water Column (OWC) converter has excelled. Fundamentally, the OWC is composed by a hydropneumatic chamber, a turbine duct, a turbine and an electric generator. The chamber is opened below the sea water free surface, while the turbine duct is opened to the atmosphere. The inner free surface oscillating movement of the water inside the chamber, produced by the incident waves, causes the air to flow alternately through the turbine installed in the turbine duct, triggering an electric generator. A representation of the OWC device is set forth in Fig. 1.

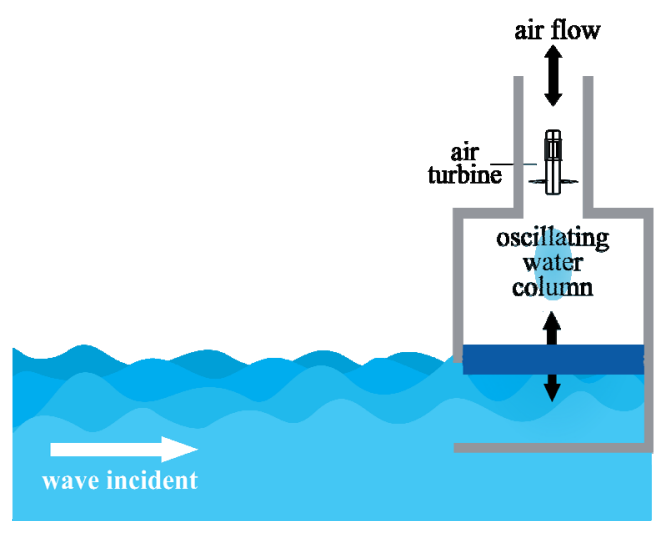

Figure 1. Oscillating water column device.

Among the methodologies used for the computational modeling of the OWC operating principle, the Piston Methodology was used in El Marjani et al. (2008). In this numerical approach only the OWC converter is considered, so only the air flow inside the device is reproduced. As a boundary condition, a prescribed vertical velocity is applied to the lower part of the computational domain, reproducing the piston effect caused by the oscillatory movement of the water column inner free surface.

The Piston Methodology was also used by Barakaz and El Marjani (2016), where a onedimensional model was used to describe the OWC behavior. In De Oliveira et al. (2017) this methodology was used in the verification of an OWC two-dimensional computational model. These studies have proved the effectiveness of the piston methodology in representing the physical phenomena involved in the operation of this type of converter.

Gomes et al. (2009) presented comparative studies between the Piston Methodology and the VOF Methodology. The acronym VOF refers to the Volume of Fluid method, through which the OWC device is simulated within a wave tank, allowing to consider the interaction between water and air.

Among the phenomena that occur during the OWC device operation, the static pressure behavior is one of the most important, because it is through it that it is possible to estimate its available power and efficiency. Thus, the objective of this research is to evaluate this behavior inside the OWC converter by imposing a monochromatic wave as input boundary condition.

A simplification adopted for this task is the use of the axisymmetric model during the numerical simulations, since it allows the construction of only half of the domain to be simulated and obtains the remainder through the revolution of the twodimensional geometry, making the flow threedimensional.

\section{MATHEMATICAL AND NUMERICAL MODELS}

The mathematical modeling of this problem consisted in the use of the conservation equations of mass and momentum allied to the $\kappa-\varepsilon$ turbulence model (Versteeg and Malalasekera, 1999):

$$
\begin{gathered}
\nabla(\rho \vec{v})=0 \\
\frac{\partial(\rho \vec{v})}{\partial t}+(\nabla \rho \vec{v}) \vec{v}=-\nabla p+\left(\mu+\mu_{\mathrm{t}}\right)\left(\nabla^{2} \vec{v}\right)+S \\
\mu_{\mathrm{t}}=\rho \mathrm{C}_{\mu} \frac{\kappa^{2}}{\varepsilon}
\end{gathered}
$$

where $\vec{v}$ is the velocity vector $(\mathrm{m} / \mathrm{s}), \rho$ is the density $\left(\mathrm{kg} / \mathrm{m}^{3}\right), \mathrm{p}$ is the pressure $\left(\mathrm{N} / \mathrm{m}^{2}\right), \mu$ and $\mu_{\mathrm{t}}$ are the dynamic and eddy viscosity $(\mathrm{kg} / \mathrm{m} . \mathrm{s}), \mathrm{S}$ is the source 
of the momentum $\left(\mathrm{N} / \mathrm{m}^{3}\right), t$ is the time (s), $\mathrm{C} \mu=0.09$ is a dimensionless constant, $\kappa$ the turbulent kinetic energy $\left(\mathrm{m}^{2} / \mathrm{s}^{2}\right)$ and $\varepsilon$ is the energy dissipation rate $\left(\mathrm{m}^{2} / \mathrm{s}^{3}\right)$, where both can be obtained from the following transport equations, respectively:

$$
\begin{array}{r}
\frac{\partial(\rho \kappa)}{\partial t}+(\nabla \rho \kappa) \vec{v}=\nabla\left[\left(\mu+\frac{\mu_{t}}{\sigma_{\kappa}}\right) \nabla \kappa\right]+G_{\kappa}- \\
-\rho \varepsilon+S_{\kappa} \\
\frac{\partial(\rho \varepsilon)}{\partial t}+(\nabla \rho \varepsilon) \vec{v}=\nabla\left[\left(\mu+\frac{\mu_{t}}{\sigma_{\varepsilon}}\right) \nabla \varepsilon\right]+ \\
+C_{\varepsilon 1} \frac{\varepsilon}{\kappa} G_{\kappa}-C_{\varepsilon 2} \rho \frac{\varepsilon^{2}}{\kappa}+S_{\varepsilon}
\end{array}
$$

where $\mathrm{C}_{\varepsilon 1}=1.44, \mathrm{C}_{\varepsilon 2}=1.92, \sigma_{\kappa}=1.00$ and $\sigma_{\varepsilon}=1.30$ are standard k- $\varepsilon$ model constants; $\mathrm{G}_{\kappa}$ is the turbulent kinetic energy generation due to the medium velocity gradient $(\mathrm{Pa} / \mathrm{s})$; and $\mathrm{S}_{\mathrm{\kappa}}$ and $\mathrm{S}_{\varepsilon}$ represent the kinetic energy source term $(\mathrm{Pa} / \mathrm{s})$ and its turbulent dissipation $\left(\mathrm{Pa} / \mathrm{s}^{2}\right)$, respectively.

To solve the conservation equations, the commercial code, based on the Finite Volume Method (FVM), FLUENT was adopted. In all numerical simulations it was adopted the first order upwind scheme and the pressure staggering option (PRESTO) scheme, for the spatial discretization of advective and pressure terms, respectively. In turn, the pressure-velocity coupling was performed by pressure-implicit with splitting of operators (PISO) method. Finally, the calculations were considered converged when the residuals for the conservation equations of mass and momentum reached values smaller than $10^{-5}$.

\section{COMPUTATIONAL DOMAIN}

The employed computational domain is twodimensional and axisymmetric. In order to assist in the analysis, a straight duct was simulated to evaluate the behavior of the static pressure with the absence of localized pressure losses. In this case the adopted dimensions were $\mathrm{R} 1=6 \mathrm{~m}, \mathrm{R} 2=6 \mathrm{~m}$ and $\mathrm{L}=15 \mathrm{~m}$ (Fig. 2a). In addition, a domain representing a CAO converter, with chamber and turbine duct, was also considered (Fig. 2c).
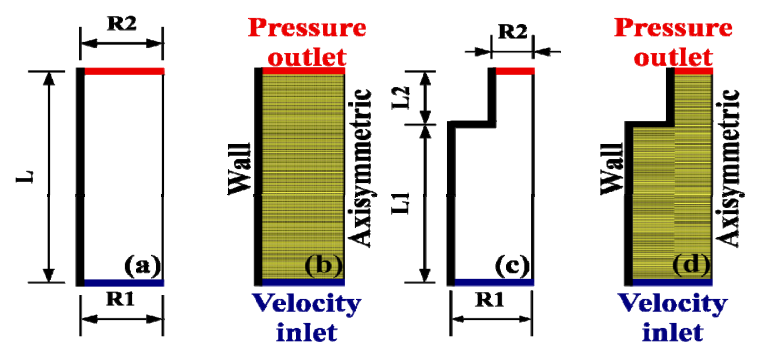

Figure 2. Computational domain: (a, b) straight duct and (c, d) OWC device.
In the OWC domain (Fig. 2c), several area ratios were used to evaluate the localized pressure drop influence on static pressure. The dimensions used are based on the values presented by De Oliveira et al. (2017), being showed in Tab. 1.

Table 1. Dimensions of the OWC domain.

\begin{tabular}{|c|c|c|c|c|}
\hline Geometry & L1 $(\mathrm{m})$ & $\mathrm{L} 2(\mathrm{~m})$ & $\mathrm{R} 1(\mathrm{~m})$ & $\mathrm{R} 2(\mathrm{~m})$ \\
\hline 1 & 10.00 & 5.00 & 6.00 & 5.00 \\
\hline 2 & 10.00 & 5.00 & 6.00 & 4.00 \\
\hline 3 & 10.00 & 5.00 & 6.00 & 3.00 \\
\hline 4 & 10.00 & 5.00 & 6.00 & 2.00 \\
\hline 5 & 10.00 & 5.00 & 6.00 & 1.15 \\
\hline 6 & 10.00 & 5.00 & 6.00 & 1.00 \\
\hline
\end{tabular}

\section{MESH DISCRETIZATION AND BOUNDARY CONDITIONS}

Geometry construction and mesh generation were performed with the GAMBIT software (see Figs. $2 \mathrm{~b}$ and $2 \mathrm{~d}$ ). The computational domains were discretized with quadrilateral elements of size 0.04 $\mathrm{m}$, determined by mesh independence test, generating regular meshes with total number of volumes between 40,000 and 50,000 units. The mesh independence test was performed with the geometry 5 of Table 1, being the maximum velocity monitored in the computational domain. The results are shown in Fig. 3, where the highlighted point indicates the mesh selected for the simulations.

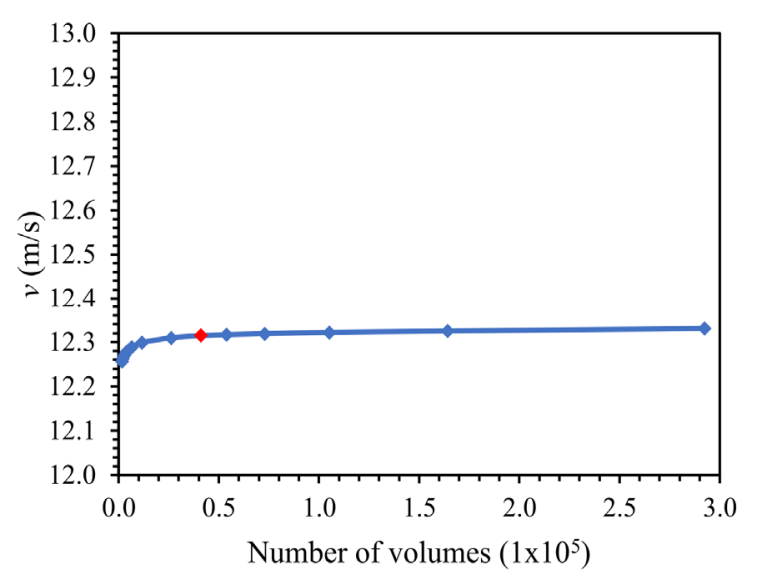

Figure 3. Mesh independence test.

To represent the air vertical velocity variation at the inlet (see Figs. $2 \mathrm{~b}$ and $2 \mathrm{c}$ ) of the hydropneumatic chamber, velocity values generated by the monochromatic wave function used in Gomes et al. (2009):

$$
\mathrm{v}(t)=\frac{H \pi}{T} \cos \left(\frac{2 \pi t}{T}\right)
$$

where $\mathrm{v}$ is the wave velocity $(\mathrm{m} / \mathrm{s}), H$ is the wave height (m), $T$ is the wave period (s) and $t$ is the time (s). As in Gomes et al. (2009), $H=0.14 \mathrm{~m}$ and $T=$ 
$0.81 \mathrm{~s}$ were used, representing a laboratory wave. The time step applied was $0.01 \mathrm{~s}$ for $6 \mathrm{~s}$.

For the other boundary conditions, it is considered as the axis of symmetry axisymmetric, atmospheric pressure in the turbine duct outlet and condition does non-slip on the wall where, as the surface roughness, we adopted a smooth surface. These conditions can be seen in Figs. $2 b$ and $2 d$.

It is worth mentioning that according to FLUENT 12.0 User's Guide (2009), for the application of the axisymmetric condition it is necessary that the axis of symmetry be the x-axis. This prevents negative volumes generated in domain.

\section{NUMERICAL MODEL VERIFICATION}

The proposed numerical model verification occurred in two ways, in the first case a constant velocity was imposed as an input boundary condition in the domain of geometry 5 and the pressure drop between the input and the output of the domain was calculated. The velocity magnitude imposed was $0.54299 \mathrm{~m} / \mathrm{s}$, higher velocity obtained through Eq. (6).

In the second verification, a three-dimensional geometry with the same dimensions of the revolutionized geometry adopted for the axisymmetric model was generated, and the values obtained from Eq. (6) were imposed as prescribed velocity boundary condition, then the pressure drop of the three-dimensional domain and the axisymmetric domain were compared. In this way, both the numerical model and the axisymmetric condition could be verified. In both cases the hydrostatic pressure component was neglected because it was a constant value.

In the pressure drop analytical calculation, for steady flow, the Bernoulli equation, available in Fox and McDonald (2006), was applied:

$$
P_{1}+\rho \frac{v_{1}^{2}}{2}+\rho g Z_{1}=P_{2}+\rho \frac{v_{2}^{2}}{2}+\rho g Z_{2}+H_{T}
$$

where $P$ is the static pressure $(\mathrm{Pa}), \mathrm{g}$ is the gravity acceleration $\left(\mathrm{m} / \mathrm{s}^{2}\right), Z$ is the height of the point considered $(\mathrm{m}), v$ is the fluid velocity $(\mathrm{m} / \mathrm{s}), H_{T}$ is the total head loss $(\mathrm{Pa})$ and indices 1 and 2 indicate the inlet (blue line in Fig. 2) and the outlet (red line of Fig. 2) of the domain, respectively.

The total head loss is presented by Çengel and Cimbala (2007):

$$
H_{T}=\rho\left(K_{P}+f \frac{L}{D}\right) \frac{v_{2}^{2}}{2}
$$

where $K_{P}$ is a dimensionless coefficient which indicates the minor loss, $L$ is the section length with constant diameter $(\mathrm{m}), D$ is the geometry diameter (m) and $f$ is a dimensionless factor that indicates the friction loss, whose value, for turbulent flows, can be obtained by the Colebrook equation, available in Fox and McDonald (2006):

$$
\frac{1}{f^{0.5}}=-2.0 \log \left(\frac{e / D}{3.7}+\frac{2.51}{R_{e} f^{0.5}}\right)
$$

where e is the wall roughness $(\mathrm{m})$ and $\mathrm{Re}$ is the Reynolds number:

$$
R_{e}=\frac{\rho v D}{\mu}
$$

For abrupt expansions and contractions, as in this case, the minor loss coefficient can be determined from Fig. 4.

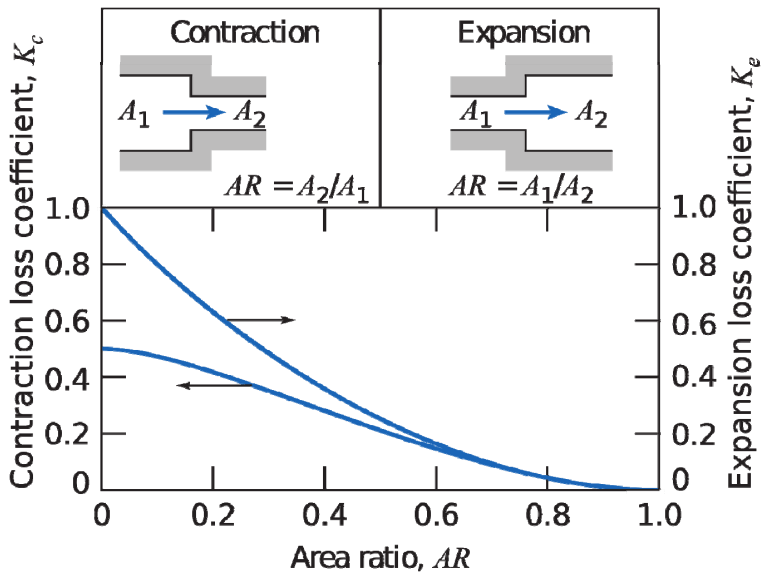

Figure 4. Loss coefficients for flow through sudden area changes (Fox and McDonald, 2006).

In Fig. 5 it is possible to compare the pressure drop results by imposing a constant velocity as inlet boundary condition in the computational domain.

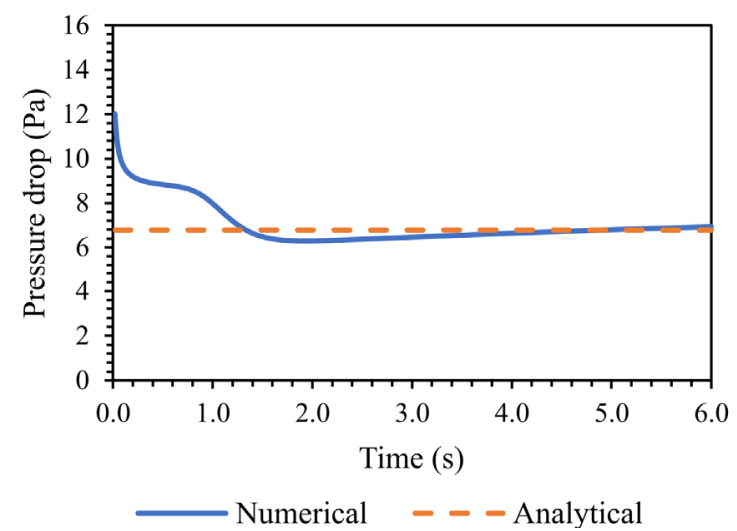

Figure 5. Pressure drop: analytical solution vs numerical solution.

When stabilizing, the numerical solution presented a difference of $2 \%$ in relation to the analytical solution, which was considered acceptable.

After that, imposing Eq. (6) as a prescribed 
velocity boundary condition, the comparison of the pressure drop between the three-dimensional domain and the axisymmetric domain can be observed in Fig. 6 .

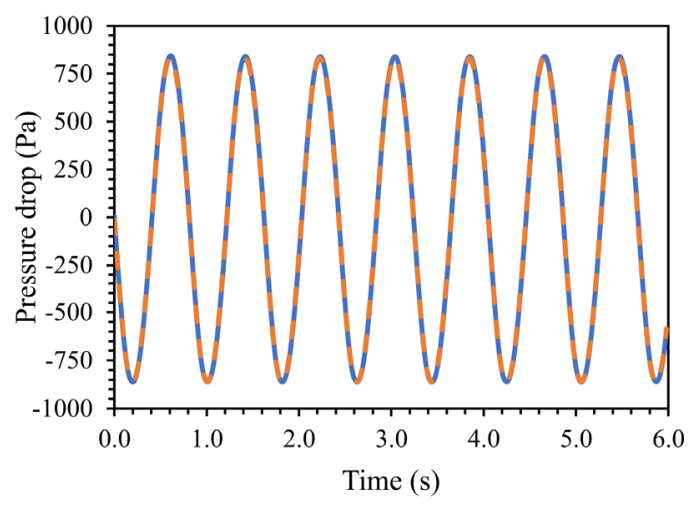

Three-dimensional --- Axisymmetric

Figure 6. Pressure drop: three-dimensional domain vs axisymmetric domain.

In Fig. 6, the pressure drop difference of $1 \%$ shows that there are no significant differences between the axisymmetric domain and the threedimensional domain. The advantage of the axisymmetric domain lies in the processing time and computational effort required, because while it took approximately $33 \mathrm{~min}$ by simulation the threedimensional domain took approximately $2655 \mathrm{~min}$, or slightly more than $44 \mathrm{~h}$. Its disadvantage lies in limiting the domain geometry.

Considering the results obtained in Figs. 5 and 6 it is possible to state that the axisymmetric computational model for the OWC converter was duly verified.

\section{RESULTS AND DISCUSSIONS}

As the static pressure at the inlet of the evaluated domains is the major contribution in the pressure drop, it will be the main component to be analyzed. It can be analytically obtained, for an incompressible flow with oscillating movement, as follows:

$$
P=\sum \frac{F}{A}=\sum \frac{m \cdot a}{A}
$$

where $F$ is the force $(\mathrm{N}), A$ is the cross-sectional area $\left(\mathrm{m}^{2}\right), a$ is the fluid acceleration $\left(\mathrm{m} / \mathrm{s}^{2}\right)$ and $m$ is the fluid mass $(\mathrm{kg})$.

As the flow is incompressible, then the fluid density is constant, so the fluid mass can be obtained as follows:

$$
m=\rho V
$$

being $V$ the domain volume $\left(\mathrm{m}^{3}\right)$.

The flow acceleration, in this case, can be obtained by deriving Eq. (6), thus we have:

$$
a(t)=-2 \frac{H \pi^{2}}{T^{2}} \sin \left(\frac{2 \pi t}{T}\right)
$$

When applying Eq. (13) in Eq. (11), for the straight duct domain (see Figs $2 \mathrm{a}$ and $2 \mathrm{~b}$ ), it was possible to analytically determine the static pressure at the domain inlet. In Fig. 7 these values are compared to those obtained numerically.

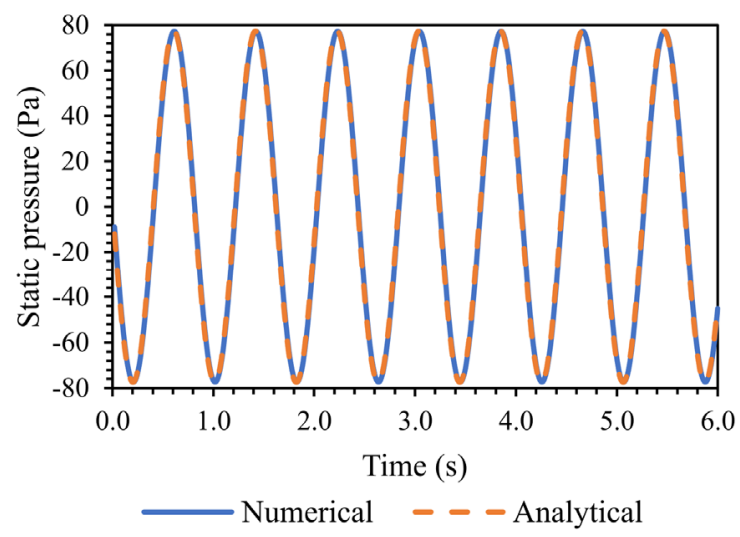

Figure 7. Static pressure at the inlet of the straight duct domain.

The numerical and analytical solutions result for the static pressure at the straight duct domain inlet, shown in Fig. 7, presented $0.12 \%$ difference between the average values of pressure. In the wave crests we observed $0.11 \%$ difference, whereas in the wave trough registered $0.10 \%$ difference. This proves the effectiveness of the use of Eq. (11) in the flows in domains without changes of area with harmonic motion.

In its turn, the geometric configurations with area change presented greater differences between the numerical and analytical solutions. For a better evaluation, the average differences and the differences between the wave crests and between the wave trough obtained from the numerical and analytical results were measured. These differences, for the static pressure at the domain entrance, can be observed in Tab. 2.

Table 2. Differences between numerical and analytical solutions.

\begin{tabular}{|c|c|c|c|c|}
\hline Geometry & $\begin{array}{c}\text { Area } \\
\text { ratio } \\
\left(A_{2} / A_{1}\right)\end{array}$ & $\begin{array}{c}\text { Average } \\
\text { difference }\end{array}$ & $\begin{array}{c}\text { Wave crest } \\
\text { difference }\end{array}$ & $\begin{array}{c}\text { Wave } \\
\text { trough } \\
\text { difference }\end{array}$ \\
\hline 1 & 0.694 & $2.08 \%$ & $2.06 \%$ & $2.09 \%$ \\
\hline 2 & 0.444 & $6.73 \%$ & $6.70 \%$ & $6.74 \%$ \\
\hline 3 & 0.250 & $12.18 \%$ & $12.09 \%$ & $12.17 \%$ \\
\hline 4 & 0.111 & $15.69 \%$ & $15.37 \%$ & $15.67 \%$ \\
\hline 5 & 0.037 & $15.15 \%$ & $11.23 \%$ & $14.81 \%$ \\
\hline 6 & 0.028 & $15.29 \%$ & $10.28 \%$ & $14.02 \%$ \\
\hline
\end{tabular}

The minor loss coefficients, determined for stationary flows, are not applicable to the differences between peaks generated in geometries with area 
change. When observing Eq. (8), one can realize that the head losses are dependent on the flow velocity.

In this specific problem the velocity is a cosine function while the acceleration is sinusoidal. As the static pressure is obtained from the acceleration, there is no way that the losses represented in Eq. (8) suppress the differences exposed in Tab. 2. This is best evidenced in Fig. 8.

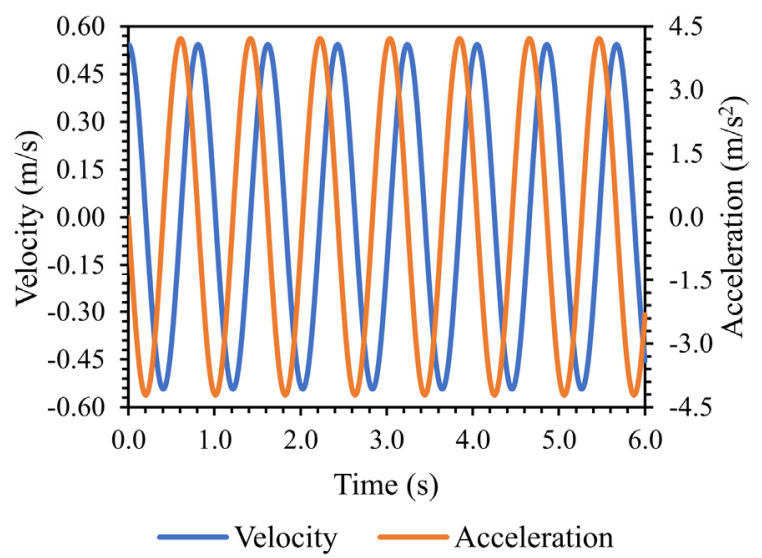

Figure 8. Comparison of the speed and acceleration functions position.

An adjustment was made for the static pressure at the domain inlet for the geometries with area change. The adjustment was done by multiplying the largest static pressure component by a constant until the difference between the crests and the troughs of the analytical and numerical solutions were less than $0.01 \%$. In Fig. 9 it is possible to consult the values applied for the adjustment factor.

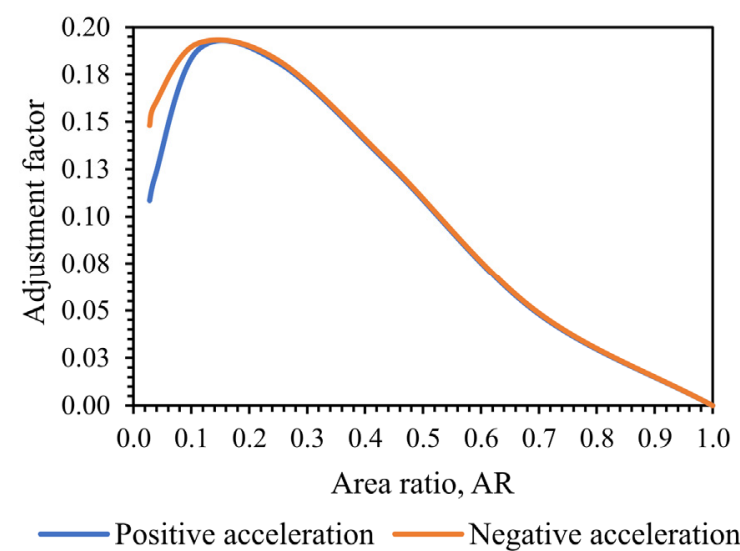

Figure 9. Static pressure adjustment factor.

It is assumed that this adjustment is necessary, mainly due to the effects of boundary layer separation and reattachment, which generate vortices that affect the static pressure. These effects are very difficult to predict analytically and can cause considerable differences in results. In Fig. 10 the magnitude of the vorticity generated in the geometric configurations with area change can be visualized.

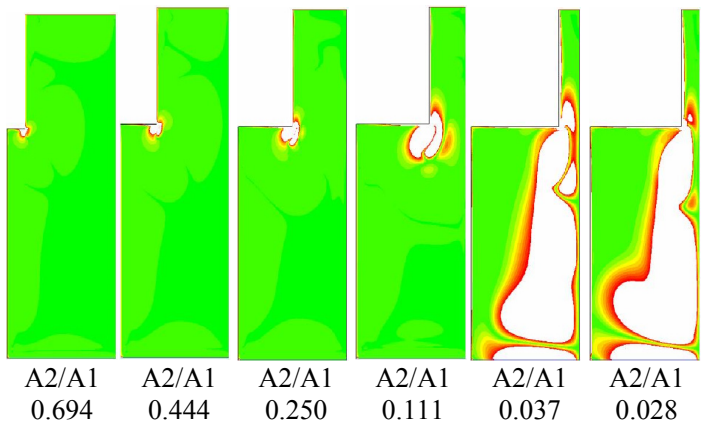

Figure 10 . Vorticity field at time $t=5.5 \mathrm{~s}$.

\section{CONCLUSIONS}

From Tab. 2 it is possible to observe that, in cases with a change of area, the smaller the outlet area in relation to the inlet area, the greater the difference between the numerical and analytical solutions, precisely because there is no term in Eq. (11) that considers the effects of the generated vorticity in the domains. It is also possible to observe that the differences between crests, troughs and averages are approximately equal for area ratios of up to 0.11 and from this have a relatively distinct behavior.

Figure 8 shows that the differences between crests and troughs of the numerical and analytical solutions can't be satisfied by the pressure losses of Eq. (8), since the velocity and acceleration functions have a natural lag.

It is assumed that the adjustment behavior, observed in Fig. 9, has a change in area ratios smaller than 0.11 because from this value the vorticity phenomenon is so intensified that it reaches the inlet region of the domain, which can be evidenced in Fig. 10. Thus, the low pressure regions generated by the vortices influence the average values of the pressures monitored at the inlet of the domain, changing the behavior of the curves exposed in Fig. 9.

It became evident that in oscillating flows the static pressure is dependent of its acceleration. It was also observed that in domains with a change of area, the area to be used in the calculation of the static pressure is smaller than the area of the geometry, because the flow becomes influenced by the low pressure regions generated by the vortices and flows through a smaller area, delimited by this phenomenon.

In future work, it is recommended to simulate other area ratios in order to confirm the behavior observed in Fig. 9. It is also necessary a more detailed study about the vorticity influence over the static pressure in domains with area ratios of less than 0.11 . In addition, an experimental study would be important to validate the information analyzed here. 


\section{ACKNOWLEDGEMENTS}

The authors thank the Coordenação de Aperfeiçoamento de Pessoal de Nivel Superior Brasil (CAPES) - Código de Financiamento 001 and the Fundação de Amparo à Pesquisa do Rio Grande do Sul (FAPERGS) - Edital 02/2017 - PqG: 17/25510001 - 111-2. E. D. dos Santos and L. A. Isoldi are grateful to the Conselho Nacional de Pesquisa $e$ Desenvolvimento (CNPq) for their Research Productivity grants.

\section{REFERENCES}

Çengel, Y. A., and Cimbala, J. M., 2007, Fluid Mechanics: Fundamentals and Applications, McGraw-Hill.

Barakaz, A., and El Marjani, A., 2016, The Oscillatory Free Water Surface Motion Inside OWC Chamber for Wave Energy Conversion, in: Preceeding of 2016 IEEE International Renewable and Sustainable Energy Conference.

De Oliveira, S. S., Pinto jr., E. A., Oleinik, P. H., Rodrigues, L., Gomes, M. Das N., Rocha, L. A. O., Dos Santos, E. D., Marques, W. C., and Isoldi, L. A., 2017, Verificação de um Modelo Computacional Proposto para um Conversor de Energia do Tipo Coluna de Água Oscilante Considerando Dados de Estado de Mar, in: XXXVIII Iberian Latin-American Congress on Computational Methods in Engineering. (in Portuguese)

El Marjani, A., Ruiz, F. C., Rodriguez, M. A., and Santos, M. T. P., 2008, Numerical Modelling in Wave Energy Conversion Systems, Energy, Vol. 85, pp. 1391-1256.

Falcão, A. F. O., and Henriques, J. C. C., 2016, Oscillating-Water-Column Wave Energy Converters and Air Turbines: a Review, Renewable Energy, Vol. 85, pp. 1391-1424.

Fluent 12.0, 2009, User's Guide.

Fox, R. W., and McDonald, A. T., 2004, Introdution to Fluid Mechanics, John Wiley and Sons.

Gomes, M. das N., Olinto, C. R., Isoldi, L. A., Souza, J. A., and Rocha, L. A. O., 2009, Computational Modeling of the Air-Flow in an Oscillating Water Column System, in: Proceedings of 20th International Congress of Mechanical Engineering.

Jenniches, S., 2018, Assessing the Regional Economic Impacts of Renewable Energy Sources - A Literature Review, Renewable and Sustainable Energy Reviews, Vol. 93, pp. 35-51.

Lisboa, R. C., Teixeira, P. R. F., Torres, F. R., and Didier, E., 2018, Numerical Evaluation of the Power Output of an Oscillating Water Column Wave Energy Converter Installed in the Southern Brazilian Coast, Energy, Vol. 162, pp. 1115-1124.

Versteeg, H. K., and Malalasekera, W, 1999, An Introduction to Computational Fluid Dynamics, Longman Scientific \& Technical. 